\title{
Metachronous inguinal hernias in children
}

\author{
Malik Samarasinghe', Ranjan Dias ${ }^{2}$ \\ The Ceylon Journal of Medical Science 2002; 45: 35-37
}

\begin{abstract}
Introduction: Hernia developing in the contralateral groin in children presenting with unilateral inguinal hernia is a recognized problem. There is no consensus regarding the need for exploration of the contralateral groin in children presenting with a unilateral hernia.
\end{abstract}

Objectives: To study the incidence of metachronous inguinal hernia and to assess the justifiability of not exploring the contralateral groin.

Methods: All children operated for unilateral inguinal hernia in our unit between April 1995 and April 1998 were asked to present themselves for review in April 2000.

Results: Hundred and forty six of the 247 children operated turned up for review. There were $96(66 \%)$ boys and $50(34 \%)$ girls. The ages ranged from 54 days to 11 years. Eight of the 50 girls (16\%) and 14 of the 96 boys (15\%) developed metachronous inguinal hernias. Metachronous hernias developed in 5 of the 42 children (12\%) who had their first operation at the age of 2 years or earlier.

Conclusion: Routine exploration of the contralateral groin of all children cannot be justified as only $15 \%$ developed metachronous hernias. Some surgeons are selective and explore the contralateral groins of all girls and in boys under 2 years. This policy also could not be justified as the incidence of metachronous hernia was equal in both sexes and was not higher in children of 2 years or younger. We recommend exploring the symptomatic groin only.

\section{Introduction}

Hernias developing in the contralateral groin (metachronous herria) in children presenting with a unilateral inguinal hernia is a recognized problem. There is no consensus regarding the management of the asymptomatic groin in children presenting with a unilateral inguinal hernia. Many current surgeons advocate a selective rather than a routine exploration of the contralateral groin. However it has been our policy and of some others to operate on the symptomatic groin only.

The objectives of our study were to evaluate the incidence of a contralateral inguinal hernia (metachronous.hernia) developing in the children we had operated on for a unilateral hernia and to assess the justifiability of not exploring the contralateral groin.

\section{Methods}

All children operated for unilateral inguinal hernia in the University Surgical Unit of the Lady Ridgeway Hospital for Children between April 1995 and April 1998 were asked to present themselves for review in April 2000. They were examined by one of the authors. Children with ascites, ventriculoperitoneal shunts and connective tissue disorders were excluded from the study.

\section{Results}

Two hundred and forty seven children were operated for a unilateral inguinal hernia between April 1995 and April 1998. Hundred and forty six $(60 \%)$ children presented for review. There were $96(66 \%)$ boys and $50(34 \%)$ girls. The ages ranged from 54 days to 11 years. Table 1 shows the age distribution at the time of the first operation. 
Table 1

Distribution of age at first herniotomy

\begin{tabular}{|c|c|}
\hline $\begin{array}{l}\text { Age (years) } \\
\text { at first operation }\end{array}$ & No. of patients \\
\hline $0-1$ & 14 \\
\hline $1-2$ & 28 \\
\hline $2-3$ & 8 \\
\hline $3-4$ & 9 \\
\hline $4-5$ & 21 \\
\hline $5-6$ & 16 \\
\hline $6-7$ & 23 \\
\hline $7-8$ & 5 \\
\hline $8-9$ & 7 \\
\hline $9-10$ & 4 \\
\hline $10-11$ & 4 \\
\hline $11-12$ & 7 \\
\hline
\end{tabular}

At review 22 children (15\%) had a subsequent hemiotomy in the contralateral groin, or presented with a metachronous hernia. Eight of these were girls and 14 were boys, making the incidence of metachronous hernia in girls $16 \%$ and in boys $15 \%$. The distribution of metachronous hernia according to the age at the first operation is shown in Table 2. Five of the 42 children (12\%) who had their first hemiotomy at the age of 2 years or earlier developed metachronous inguinal hernias.

Table 2

Distribution of patients with metachronous inguinal hernia according to the age at first operation

\begin{tabular}{|l|c|c|}
\hline $\begin{array}{l}\text { Age (years) } \\
\text { at first } \\
\text { operation }\end{array}$ & $\begin{array}{l}\text { No. with no } \\
\text { metachronus } \\
\text { hernia }\end{array}$ & $\begin{array}{l}\text { No. with } \\
\text { metachronus } \\
\text { hernias }\end{array}$ \\
\hline $0-1$ & 12 & 2 \\
\hline $1-2$ & 25 & 3 \\
\hline $2-3$ & 6 & 2 \\
\hline $3-4$ & 6 & 2 \\
\hline $4-5$ & 15 & 6 \\
\hline $5-6$ & 12 & 4 \\
\hline $6-7$ & 21 & 2 \\
\hline
\end{tabular}

\section{Discussion}

Several approaches to manage the problem of metachronous hernia in children presenting with unilateral inguinal hernias have been used. They are (a) routine exploration of the contralateral groin, (b) selective exploration of the contralateral groin, (c) not exploring the contralateral groin and performing a herniotomy if a metachronous hernia develops, and (d) evaluation of the contralateral groin, for a potenital hernia by laparoscopy or pneumoperitonography. Routine exploration of the contralateral groin was justified by the demonstration of a $50 \%-90 \%$ incidence of a contralateral patent processus vaginalis in several series $(1,2)$. However subsequent followup series have demonstrated a much lower incidence $(20 \%)$ of metachronous hernia developing, if the contralateral groin is not explored (1). Exploring the contralateral groin in addition to prolonging the surgery also puts the vas deferens and the testicular vessels of the male child at risk. Therefore most surgeons have given up routine exploration of the contralateral groin. We had a $15 \%$ incidence of metachronous hernia, which justifies the position against routine exploration of the contralateral groin. Other factors such as female sex, left sided primary hernia, and age under 2 years have been implicated by different workers as predictors of metachronous hernia (1). Such findings have led to the recomrtiendation of a selective approach to contralateral groin exploration. A standard text book of paediatric surgery recommends contralateral groin exploration in all males under 2 years and in females of any age (1). However our study demonstrated very close and low incidence of metachronous hernia in girls and boys, $16 \%$ ( 8 out of 50 ) and $15 \%$ ( 14 out of 96 ) respectively. Therefore we cannot justify the recommendation of exploring the asymptomatic groin of all girls. Exploring the contralateral groin of boys under 2 years was also difficult to justify as our study revealed an incidence of metachronous hernia of only $12 \%$ in children who were 2 years or younger at the first operation. These results were similar to those of 2 recently published series. Kemmotsu it al in a study 
involving 1001 children aged 1 to 11 years found an overall incidence of metachronous hernia developing in $11.6 \%$ (3). Ballantyne et al in a study of 181 infants detected metachronous hernia in only $7.7 \%$ (4). Both these studies show no change in the incidence of metachronous hernia with age, sex or the side of the primary hernia. Both studies concluded by not recommending contralateral groin exploration.

Therefore in the Sri Lankan setting where access to laparoscopy and pneumoperitonography is limited we recommend the policy of operating only the symptomatic groin in children presenting with a unilateral inguinal hernia.

\section{Acknowledgements}

We wish to thank Drs. H. M. A. Priyangani, M. U. W. Kumara, E. Q. Veerasingam, M. A. B. Fernando, A. C. V. Silva, G. S. Perera, S. M. D. Chandraguptta, and M. A. Aniffdeen for helping with the collection of data.

This study was presented at the Annual Scientific
Session of the College of Surgeons of Sri Lanka in August 2000.

\section{References}

1. Thomas R. Weber, Tom F. Tracy Jr. Groin hernias and hydroceles. In: Keith $W$. Ashcraft, Thomas M. Holder, eds. Pediatric Surgery. 2nd ed. Philadelphia: W. B. Saunders Company, 1993: 562-570.

2. Zona J.Z. The incidence of positive contralateral inguinal exploration among preschool children - a retrospective and prospective study. Journal of Paediatric Surgery 1996; 31: 656-660.

3. Kemmotsu H., Oshima Y., Joe K., Mauri T. The features of contralateral manifestations after the repair of unilateral inguinal hernia. Journal of Paediatric Surgery 1998; 33: 1099 1102.

4. Ballantyne A., Jawaheer G., Munro E.D. Contralateral groin exploration is not justified in infants with an unilateral inguinal hernia. British Journal of Surgery 2001; 88: 720-723. 